\title{
The Variations in the Level of Angiotensin II Between Subjects in Ajloun City and the Dead Sea Impact Hypertension Parameters
}

\author{
Taghreed A. Al-Refaai \\ Dr. Basel Naeem Fandy Al-Rawashdeh \\ Mai Abu Salem \\ Dyana Blokh \\ Reham Mrayat \\ Ahlam Nasri Damen Al-Hamaideh \\ Jaafar Abu Abeeleh \\ Royal Medical Services (RMS). Jordan
}

Mustafa Ahmad Al-Shehabat

Department of physiology, Faculty of Medicine, Jordan University of Science and technology, Jordan

Ahed J Alkhatib

Jordan University of Science and technology, Jordan

Mahmoud abu abeeleh

The University of Jordan, Jordan

doi: 10.19044/esj.2016.v13n3p455 URL:http://dx.doi.org/10.19044/esj.2016.v13n3p455

\begin{abstract}
Introduction: Jordan has a unique array of diversity among which having the deepest level in the world, the Dead Sea and an area with high attitudes in Ajloun City which gives us a great chance to study the biological effects on hypertension and possible impacts in selecting the appropriate treatment.

Study objectives: to explore the impacts of variations of attitudes in hypertension and the level of beta blockers through studying the level of angiotensin II among study participants and to investigate if the patterns of anti-hypertensive treatments are impacted.

Methods and subjects: a cross-sectional study design was carried out among participants from the two different areas. From each area, a total of 500 participants were recruited and surveyed through a questionnaire. Blood pressure was measured for all participants and blood samples were withdrawn to carry out the testing of angiotensin II. Data were analyzed
\end{abstract}


statistically based on the appropriate software including excel and SPSS. The relationships were examined according to independent T-Test. Significance was considered according to $\mathrm{p}<0.05$.

Study findings: the main findings of the present study showed that no statistically significant differences were obtained for the following variables: age, weight, BMI, and waist circumferences $(\mathrm{P}>0.05)$. On the other hand, heart parameters including SBP, DBP, MBP, pulse, and PCV all of which were significantly higher in Ajloun than in the Dead Sea $(p=0.001)$ for all selected variables. The level of angiotensin II was $12.08 \pm 5.19 \mathrm{pg} / \mathrm{ml}$ in Ajloun and this was higher than that of the Dead Sea $(8.84 \pm 4.65 \mathrm{pg} / \mathrm{ml})$. The difference in the mean of angiotensin II was statistically significant $(p=0.039)$.

Conclusion: the results of the present study showed that living in high altitude compared with the lowest area in the world (the Dead Sea) exposes persons for the risks of hypertension and other cardiovascular diseases. Our findings may lead to better therapeutic strategies particularly when to prescribe angiotensin II based therapies.

Keywords: Angiotensin II, hypertension, altitude, the Dead Sea, Ajloun

\section{Introduction}

High and low altitudes are not only destinations of adventurous travelers; many people are born, live their lives and die in these regions. According to $\mathrm{WHO}$, in 1996 there were approximately 140 million people living at altitudes over $2500 \mathrm{~m}$ and there are several areas of permanent habitation at over $4000 \mathrm{~m}$ (WHO, 1996). These are in three regions of the world: the Andes of South America, the highlands of Eastern Africa, and the Himalayas of South-Central Asia, while there are hundreds of thousands of people living in low altitude regions such as the Dead Sea area in Jordan which lies $400 \mathrm{~m}$ below sea level (Royal Geographical Center, 2009). This study is concerned with the effects of continuous exposure to different altitudes on the cardiovascular system and its autonomic control, and the means by which the permanent high altitude dwellers have adapted to their environment, in addition to the effect of other variables such as the gender, race, $\mathrm{BMI}$, age on blood pressure.

The two main challenges to life at high altitude come from hypobaric hypoxia and the low ambient temperatures. Temperature decreases about $1 \mathrm{C}$ for each $150 \mathrm{~m}$ elevation, so that at $4,500 \mathrm{~m}$ temperature is roughly 30C lower than at sea level. Barometric pressure falls progressively with increasing altitude (Hainsworth et al., 2007). Up to about 2,500 m there are few if any effects of hypoxia but above 3,000 m some effects of hypoxia are 
likely to be experienced and above 4,000 m adverse effects would be experienced by most unacclimatized subjects (Grover et al., 2001).

The renin-angiotensin system (RAS) is considered as a significant factor in controlling blood pressure, electrolyte balance and body fluid homeostasis (Moltzer, 2010). Several studies have shown that the RAS is started by converting angiotensinogen into angiotensin I, and then this is converted through the effect of ACE to angiotensin II (Schuijt and Danser, 2002; Esch et al., 2010).

Hypertension is considered a main risk factor for several cardiovascular diseases including stroke, atherosclerosis, heart failure and end organ damage. Moreover, hypertension affects 1 in 3 adult Americans (Cutler et al., 2008). According to Romero and Reckelhoff (1999), although hypertension is highly prevalent, the understanding of the mechanisms involved in hypertension pathogenesis is considerably limited

Study objectives: to explore the impacts of variations of attitudes in hypertension and the level of beta blockers through studying the level of angiotensin II among study participants and to investigate if the patterns of anti-hypertensive treatments are impacted.

\section{Methodology}

Study design: a cross sectional study was followed to collect data from study participants within the same time frame.

\section{Study setting}

Two areas with different altitudes were included: the Dead Sea level area and Ajloun area, Jordan.

\section{Study sample}

A total of 1000 participants were included in this study. Of them, 500 participants were included from each area. All participants were males, matched for age grouping, and they were apparently healthy.

\section{Data collection}

Data was collected and tabulated for each participant. The variables under investigation included blood pressure, weight, height, waist circumference, heart rate per minute, the level of angiotensin II, and packed cell volume (PCV).

\section{Data analysis}

The analysis of data was carried out using SPSS version 20. Data were represented as mean and standard deviation. The relations between 
variables were computed using independent $\mathrm{T}$ test. Significance was considered at alpha $<0.05$.

\section{Results}

\section{Comparison between the Means and Standard Deviations of Blood} Pressure and other Variables in the Dead Sea and Ajloun.

As shown in table 1, no significant differences were obtained for the following variables: age, weight, $\mathrm{BMI}$, and waist circumferences $(\mathrm{P}>0.05)$. On the other hand, heart parameters including SBP, DBP, MBP, pulse, and PCV all of which were significantly higher in Ajloun than in the Dead Sea ( $p=0.001$ for all selected variables).

Table 1: Comparison between the Means and Standard Deviations of Blood Pressure and other Variables in the Dead Sea and Ajloun.

\begin{tabular}{|c|c|c|c|}
\hline \multirow[t]{2}{*}{ Variables } & Dead Sea & Ajloun & \multirow[t]{2}{*}{ P value } \\
\hline & Mean \pm std & Mean \pm std & \\
\hline Age & $17.60 \pm 0.51$ & $17.83 \pm 0.69$ & NS \\
\hline Weight/kg & $67.31 \pm 10.77$ & $67.37 \pm 10.76$ & NS \\
\hline Height/cm & $169.29 \pm 6.52$ & $169.51 \pm 7.42$ & NS \\
\hline BMI & $23.45 \pm 3.27$ & $23.42 \pm 3.22$ & NS \\
\hline Waist cir./cm & $76.37 \pm 10.26$ & $75.99 \pm 10.21$ & NS \\
\hline SBP/mmHg & $122.42 \pm 10.53$ & $125.74 \pm 10.01$ & 0.001 \\
\hline DBP/mmHg & $76.31 \pm 9.14$ & $79.62 \pm 8.43$ & 0.001 \\
\hline MBP/mmHg & $91.64 \pm 8.90$ & $94.95 \pm 8.03$ & 0.001 \\
\hline Pulse/minute & $79.74 \pm 6.17$ & $81.71 \pm 5.66$ & 0.001 \\
\hline PCV & $42.17 \pm 3.18$ & $45.27 \pm 2.18$ & 0.001 \\
\hline
\end{tabular}

\section{Comparison between Angiotensin II Concentration in Ajloun and the} Dead Sea Level

As shown in table 2 and figure 1, the level of angiotensin II was $12.08 \pm 5.19 \mathrm{pg} / \mathrm{ml}$ and this was higher than that of the Dead Sea $(8.84 \pm$ $4.65 \mathrm{pg} / \mathrm{ml})$. The difference in the mean of angiotensin II was statistically significant $(\mathrm{p}=0.039)$.

Table 2: Comparison between Angiotensin II Concentration in Ajloun and the Dead Sea Level

\begin{tabular}{|l|l|l|l|l|}
\hline Target Area & Mean \pm std & Target Area & Mean \pm std & P value \\
\hline Ajloun & $12.08 \pm 5.19$ & Dead Sea & $8.84 \pm 4.65$ & 0.039 \\
\hline
\end{tabular}




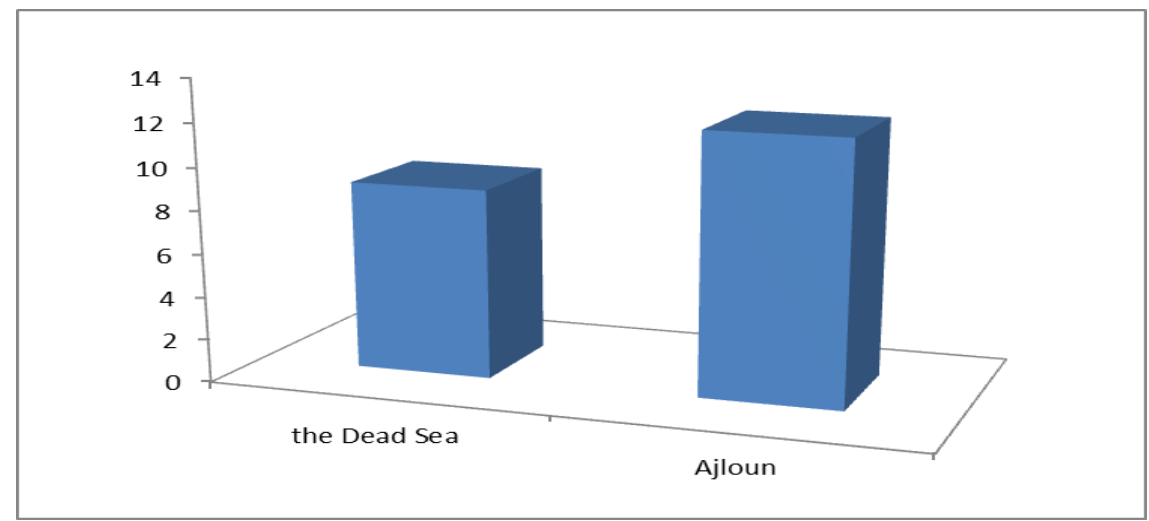

Figure 1: The level of angiotensin II in Ajloun and the Dead Sea

\section{Discussion}

The present study was conducted to achieve the following objectives to explore the impacts of variations of attitudes in hypertension and the level of beta blockers through studying the level of angiotensin II among study participants and to investigate if the patterns of anti-hypertensive treatments are impacted.

The results of the present study did not reflect any significant variations in variables related to age, height, weight, BMI, and waist circumference $(\mathrm{p}>0.05)$. These findings can be explained by taking into account that the participants were matched almost for all of these variables. accordingly this helps in evaluating the remaining findings of this study without having interfeence from personal characteristics.

The results of our study showed that the levels of the following variables SBP, DBP, MBP, pulse, and PCV were significantly higher in Ajloun than in the Dead Sea level $(p=0.001)$. This indicates the effects of altitude variations. The Dead Sea area in Jordan lies $400 \mathrm{~m}$ below sea level (Royal Geographical Center, 2009), while the elevation of Ajloun is $719 \mathrm{~m}$ (flood.net, 2016). We think that high altitude exert their effects through hypobaric hypoxia and the low ambient temperatures (Hainsworth et al., 2007). With increasing the altitudes, hypoxia is likely to have effects that lead to increased hypertension parameters and packed cell volume (Grover et al., 2001).

Our results showed that the level of angiotensin II was $12.08 \pm 5.19$ $\mathrm{pg} / \mathrm{ml}$ and this was significantly higher than that of the Dead Sea 8.84 4.65 $\mathrm{pg} / \mathrm{ml}(\mathrm{p}=0.039)$. The effect of altitude on the level of angiotensin II is obvious. We think that it is for the first time in Jordan such a study has been conducted. Our findings are consistent with other studies in which both blood pressure and angiotensin II were increased with high altitudes and that the blockage of angiotensin receptor II helped in maintaining blood pressure (Parati et al., 2014). 
Conclusion: the present study showed that high altitude compared with the lowest part in the world increased the levels of heart parameters and angiotensin II significantly, and according to this context, therapeutic options have to be considered when treating patients of these areas.

\section{References:}

1. Cutler, J.A., Sorlie, P.D., Wolz, M., Thom, T., Fields, L.E., Roccella, E.J.,(2008). Trends in hypertension prevalence, awareness, treatment, and control rates in United States adults between 1988-1994 and 1999-2004. Hypertension 52, 818-827.

2. Els Moltzer (2010). Aortic pathology and the role of the reninangiotensin system. Ph.D thesis, Erasmus University Rotterdam, ISBN: 978-90-6464-456-6.

3. Gianfranco Parati, Grzegorz Bilo, Andrea Faini, Barbara Bilo, Miriam Revera, Andrea Giuliano, Carolina Lombardi, Gianluca Caldara, Francesca Gregorini, Katarzyna Styczkiewicz, Antonella Zambon, Alberto Piperno, Pietro Amedeo Modesti, Piergiuseppe Agostoni, Giuseppe Mancia (2014). Changes in $24 \mathrm{~h}$ ambulatory blood pressure and effects of angiotensin II receptor blockade duringacute and prolonged high-altitude exposure: a randomized clinical trial. European Heart Journal, doi:10.1093/eurheartj/ehu275.

4. Grover RF, Bärtsch P. Blood. In: Hornbein TF, Schoene RB (2001). High Altitude: An Exploration of Human Adaptation. New York, NY: Marcel Dekker Inc, 161: 493-523.

5. http://www.floodmap.net/Elevation/ElevationMap/?gi=7838911, accessed in 21/12/2016.

6. Roger Hainsworth, Mark J. Drinkhill, and Maria Rivera-Chira (2007). The autonomic nervous system at high altitude. Clin. Auto. Res, 17 (1):13-19.

7. Royal Geographical Center (2009). Monitoring of the Dead Sea. Israel Marine Data Center ISRAMAR.

8. Schuijt MP, Danser AHJ (2002). Cardiac angiotensin II: an intracrine hormone? Am J Hypertens., 15:1109- 1116.

9. van Esch JHM, Gembardt F, Sterner-Kock A, Heringer-Walther S, Le TH, Lassner D, Stijnen T, Coffman TM, Schultheiss HP, Danser AHJ, Walther T (2010). Cardiac phenotype and angiotensin II levels in AT1a, AT1b and AT2 receptor single, double and triple knockouts. Cardiovasc Res, 86:401-409.

10. WHO World Health Statistics Annual 1995. World Health Organization, Geneva.. (1996). 